\title{
Diesel Exhaust Particles in the Work Environment and their Analysis
}

\author{
Mariko ONO-OGASAWARA ${ }^{1^{*}}$ and Thomas J. SMITH ${ }^{2}$ \\ ${ }^{1}$ National Institute of Industrial Health, 6-21-1 Nagao, Tama-ku, Kawasaki 214-8585, Japan \\ ${ }^{2}$ Harvard School of Public Health, Boston, MA 02215, USA
}

Received July 13, 2004 and accepted September 13, 2004

\begin{abstract}
Diesel engines are widely used in industries, for example transportation, mining, and construction, because they efficiently produce high power. In diesel exhaust particles (DEP), the number of ultrafine particles, less than around $100 \mathrm{~nm}$, is dominant in contrast to mass size distribution. Carcinogenic PAHs may be adsorbed on DEP at high concentrations. As occupational exposure usually occurs near emission sources, workers are likely to be exposed to high concentration DEP. The exhaust emissions of diesel engines have become lower by modification of the engines and fuels, and introduction of filters and catalysts, thus it has become more difficult to monitor mass and chemical components in DEP. New technology and instruments are being introduced to characterize DEP especially chemically. Recently, quick analytical methods without extraction, and continuous or semi-continuous methods have been introduced. This article will review 1) Elemental Carbon (EC) monitors, 2) analytical methods of individual PAH without solvent extraction, and 3) continuous PAH monitor, because EC and PAH are typical constituents for DEP.
\end{abstract}

Key words: DEP, Particulate matter, PAH, OC, EC

\section{Introduction}

There is a global concern about adverse health effects of particulate matter (PM) originating from diesel engines, especially when they are not operated in an optimum condition. Health effects of diesel particulate matter (DEP) have been evaluated and updated for more than two decades ${ }^{1,22}$. DEPs are categorized in $2 \mathrm{~A}$ group of human carcinogen ${ }^{1)}$. Recent research suggests diesel exhaust causes allergic effects on mice $^{3)}$ and affects spermatogenesis in growing male rats ${ }^{4)}$. Moreover, particles smaller than $100 \mathrm{~nm}$, ultrafine particles, are typically observed in DEP. Adverse health effects of ultrafine particles are a growing concern.

Diesel exhaust is a mixture of gaseous and particulate

*To whom correspondence should be addressed. substances originated from unburned fuel, lubricant oil and combustion products. Its main components are carbon monoxide $(\mathrm{CO})$, carbon dioxide $\left(\mathrm{CO}_{2}\right)$, nitrogen oxides (NOx), sulfur oxides (SOx), hydrocarbons (HC), as well as $\mathrm{PM}^{5}$. Even though the diesel engine emits lower concentrations of global warming gases such as $\mathrm{CO}$ and $\mathrm{CO}_{2}$, it emits higher concentration of NOx and PM in contrast to gasoline engine. A main constituent of DEP is elemental carbon (EC) and higher concentration of polycyclic aromatic hydrocarbons (PAHs) and their methylated, nitrated and oxygenated derivatives, functionalized polycyclic aromatic compounds (PACs) are observed in DEP. PAHs and PACs are included in polycyclic organic matter (POM), which is defined in the U.S. Clean Air Act Amendments as POM "includes organic compounds with more than one benzene ring, and which have a boiling point greater than or equal to $100^{\circ} \mathrm{C} "$ 
Diesel engines are widely used in industries, for example transportation, mining, and construction, because they efficiently produce high power. Hence, the regulations for diesel engines used for industrial and off-road applications have not been so strict as required for on-road engines. In 2001, the Ministry of Land, Infrastructure and Transport of Japan regulated the exhaust levels from construction vehicles ${ }^{6}$. Exhaust levels of NOx and PM were newly regulated and the level of $\mathrm{HC}$ and $\mathrm{CO}$ were lowered. The Ministry of Labour of Japan also presented a guideline level for PM in tunnel construction sites recommending exposures no more than $3 \mathrm{mg} / \mathrm{m}^{3}{ }^{7)}$. Even if the exhaust level from construction vehicles is lowered and PM concentration is monitored, workers in confined workplaces are susceptible to overexpose to diesel exhaust substances. Occupational exposures to DEP, where the main route of exposure is inhalation, have been reported for underground construction $^{8)}$, electric utility work ${ }^{9)}$, garage workers ${ }^{10)}$, truck drivers $^{11)}$ and others ${ }^{12-14)}$.

Internal exposure to DEP has been evaluated as a PAH exposure by the analysis of metabolites of PAHs, such as 1hydroxypyrene and other metabolites. PAH exposure includes inhalation of gaseous PAHs and skin absorption of $\mathrm{PAH}$, especially at higher temperature conditions, for example coke oven workers. Biomarkers of PAHs, such as PAHs and PAH-metabolites in urine and blood and adducts in DNA and proteins, were summarized in the review of Jongeneeren ${ }^{15)}$.

The exhaust emissions of diesel engines become lower by modification of engines and fuels and introduction of filters and catalysts, and it becomes difficult to monitor mass and chemical components in DEP. New technology and instruments are being introduced to characterize chemical and physical aspects of DEP. Various kinds of measuring methods of physical properties of fine particles have been developed and they are reviewed by Chow ${ }^{16)}$ in 1995.

In this article, new techniques applied to the analysis of DEP will be reviewed, which are designed to determine DEP chemical composition. DEP contains thousands kinds of chemical substances, both inorganic and organic. Analytical methods for the chemical substances without solvent extraction, and new continuous or semi-continuous methods have been introduced, where previously these chemical species have been analyzed after they were extracted into solution. This article reviews 1) EC monitors, 2) analytical methods for individual PAH without solvent extraction, and 3) continuous PAH monitors, because EC and PAH are typical constituents for DEP.

\section{Character of DEP}

Typical mass and number size distribution of DEP is described by Kittelson ${ }^{17)}$. The number of ultrafine particles, less than $100 \mathrm{~nm}$, is dominant in the number-size distribution in contrast to the larger particles that dominate the masssize distribution. Ultrafine particles are emitted directly from engines or generated by condensation of gaseous emissions, which is called as nucleation mode. They rapidly coagulate with larger particles or serve as nuclei of droplets in accumulation mode, therefore their residence time as independent particles is short. As occupational exposure usually occurs near emission sources, a larger amount of smaller size particles are expected to exist in work environment than in ambient environment. The adverse health effect derived from ultrafine PM should be considered in the workplaces where diesel engines are used. In the 1990 s, toxicity of inactive ultrafine particles $(<100 \mathrm{~nm})$ of insoluble materials such as $\mathrm{TiO}_{2}$, carbon black and Teflon powder at very high airborne exposures were reported ${ }^{18)}$. Because the particles were insoluble, their differences in toxicity were explained by differences in the number and surface area of the particles ${ }^{19,20}$. This toxicity was observed only for rats and could be caused by macrophage overloading with ultrafine particles, which may not be relevant for human exposures. Thus, effects of ultrafine particle in human is not well understood ${ }^{21)}$. Since association of PM2.5 and noncancer human health effect are reported ${ }^{22,23)}$ more research on ultrafine particles are being carried on.

In the tailpipe, the temperature is high enough that most of organic substances are in the gas phase. After they are emitted into the air, they undergo cooling and dilution, during which the low volatility substances are condensed or adsorbed on PM. Firstly the core of solid carbon and metals are produced in the engine cylinder, after emission high molecular weight pyrolysis products adsorb or condense on ultrafine PM, later unburned fuel or other inorganic compounds, including sulfate and water, condense or are adsorbed on the particles, and simultaneously coagulation and agglomeration of small particle occurs. The structure of a diesel particle is an aggregation of primary and spherical carbon particles coated with adsorbed and condensed products during combustion. Ishiguro et al. reported the structure of diesel particles observed with a transmission electron microscopy ${ }^{24}$. The core of spherical particle is consist of amorphous carbon and an outside layer connecting each particles has crystal structure.

The composition of DEPs depends on where and how they are collected and how the engine is operated. Typical 
composition of DEPs for a heavy-duty diesel engine tested in a heavy-duty transient cycle is described as follows: inorganic carbonaceous substances, which is named EC, are about $40 \%$ of total mass of PM, organic carbonaceous substances originating from unburned fuel and oil $30 \%$, and sulfate, water, ash and others $30 \%{ }^{5,17)}$. Inorganic carbonaceous substances are often inferred as EC, black carbon (BC) or soot. These terms are not defined by strict chemical property, and the quantities observed depend on analytical method, optical character or appearance of the material. They are considered to be the product of incomplete combustion of fuels. Most of the organic compounds in DEP are aliphatic and aromatic hydrocarbons from unburned fuel and lubricants.

PAHs, which are also derived from unburned fuel and combustion products, are considered to be important from a toxicological point of view. A large number of PAHs ranging from 2-ring naphthalene to 5- and 6-ring and higher PAHs, their alkyl substituted analogues, and their oxygenand nitrogen-containing derivatives, are emitted from motor vehicle sources. In addition, heterocyclic analogues containing ring $\mathrm{O}-, \mathrm{S}-$, and $\mathrm{N}$-atoms are possible emissions from combustion sources. The PAH, their analogues and derivatives have relatively low vapor pressures and are distributed between gas and particulate phases ${ }^{25,26)}$. In temperate climates, 2- to 4-ring PAHs are found primarily in the gas phase, but under lower temperatures, the distribution shifts toward the particulate phase. Photolysis and atmospheric reactions with $\mathrm{O}_{3}, \mathrm{NO}_{2}, \mathrm{HNO}_{3}$, and $\mathrm{N}_{2} \mathrm{O}_{5}$ have been shown to lead to loss of PAH and their derivatives on several substrates ${ }^{27)}$. Carcinogenicity of each PAH and $\mathrm{PAC}$ has been examined and 5-ring Benzo(a)pyrene is considered as a one of the most carcinogenic PAHs and has beed used as an indicator of environmental PAH exposures. Nitroarenes are by far the most mutagenic or carcinogenic in the PAH related substances ${ }^{28}$. More precise research on $\mathrm{PAH}$ and their derivatives is needed to assess the toxicity and atmospheric fate of these species.

\section{Monitoring of Elemental Carbon (EC)}

Airborne PM is originated from various sources such as combustion products, aqueous droplets, secondary generated particles and inorganic dust from soil. PM from combustion source contain many kinds of chemical substances. For DEP, as mentioned above, the content of $\mathrm{EC}$ is reported as around $40-60 \%{ }^{5,17)}$, thus the contribution of diesel engine emissions on whole $\mathrm{PM}$ in an environment is often evaluated by measurement of $\mathrm{EC}^{29-31)}$. $\mathrm{EC}$ is considered to have potential effects on health, visibility, climate, and so on. Thus, in Germany, the threshold limit value of EC was set at $0.3 \mathrm{mg} /$ $\mathrm{m}^{3}$ for non-coal mining and tunnel construction site and 0.1 $\mathrm{mg} / \mathrm{m}^{3}$ for other applications in $1997^{32}$. The American Conference of Government Industrial Hygiene (ACGIH) first proposed a Threshold Limit Value (TLV) in general occupational environment of $0.15 \mathrm{mg} / \mathrm{m}^{3}$ for DEP in its 1995 1996 Notice of Intended Changes (NIC) and the limit was later lowered to $0.05 \mathrm{mg} / \mathrm{m}^{3}$. In its $2001 \mathrm{NIC}$, the ACGIH replaced this value with a practically equivalent limit of 0.02 $\mathrm{mg} / \mathrm{m}^{3}$ expressed as EC, because the EC fraction in DEP typically constitutes about $40 \%$ of the total diesel particulate mass. But ACGIH has withdrawn DEP from the NIC in its 2003 edition of TLV list for chemical substances and physical agents. For non-coal mine industry, in August, 2003, Mine Safety and Health Administration proposed the interim limit of $0.308 \mathrm{mg} / \mathrm{m}^{3}$, measured as EC by The National Institute for Occupational Safety and Health (NIOSH) 5040 method and this limit is planned to be lowered by 2006 .

Typical measurement methods for EC are thermal methods, which were introduced in the 1980 ' $\mathrm{s}^{33,34}$. In the single sample method, PM is collected on a quartz fiber filter, and a punch removed from the filter is heated first without oxygen to remove organic carbon (OC), then heated again and the EC is oxidized with oxygen . Produced $\mathrm{CO}_{2}$ from $\mathrm{OC}$ or $\mathrm{EC}$ is determined directly by NDIR (Non-dispersive infrared) carbon dioxide analyzer ${ }^{33}, 35$ ), coulometry (electrochemical sensor) ${ }^{36,37)}$, or FID (flame ionized detector) following the catalytic reduction of $\mathrm{CO}_{2}$ to $\mathrm{CH}_{4}{ }^{38-40}$. $\mathrm{OC}$ and $\mathrm{EC}$ are terms that are determined by operational condition of thermal method. The quantities determined by different operation conditions are not equivalent.

Thermal-NDIR method has been used to monitor carbonaceous substances in suspended particulate matters in ambient air in Japan ${ }^{35)}$.

The coulometric method is applied to monitor EC in work environment in Germany ${ }^{36,37)}$. In this method, a loaded filter is treated with diluted hydrochloric acid to remove carbonate carbon, which shows a positive interference. Then the filter is heated under nitrogen at $500^{\circ} \mathrm{C}$ for $8 \mathrm{~min}$ in infrared oven. After this period, the sample chamber is cooled to room temperature, the atmosphere is changed to oxygen, and heated to $330^{\circ} \mathrm{C}$ in $0.5 \mathrm{~min}$ and subsequently to $800^{\circ} \mathrm{C}$ in $4.5 \mathrm{~min}$. Evolved carbon under nitrogen and oxygen atmospheres are defined as OC and EC, respectively. Evolved carbon under the nitrogen atmosphere is converted into $\mathrm{CO}_{2}$ by $\mathrm{CuO}$ catalyst bed at $800^{\circ} \mathrm{C}$. The $\mathrm{EC}$ heated under oxygen is evolved as $\mathrm{CO}_{2}$. As the $\mathrm{CO}_{2}$ is absorbed by the electrochemical cell solution, the resulting decrease in $\mathrm{pH}$ 


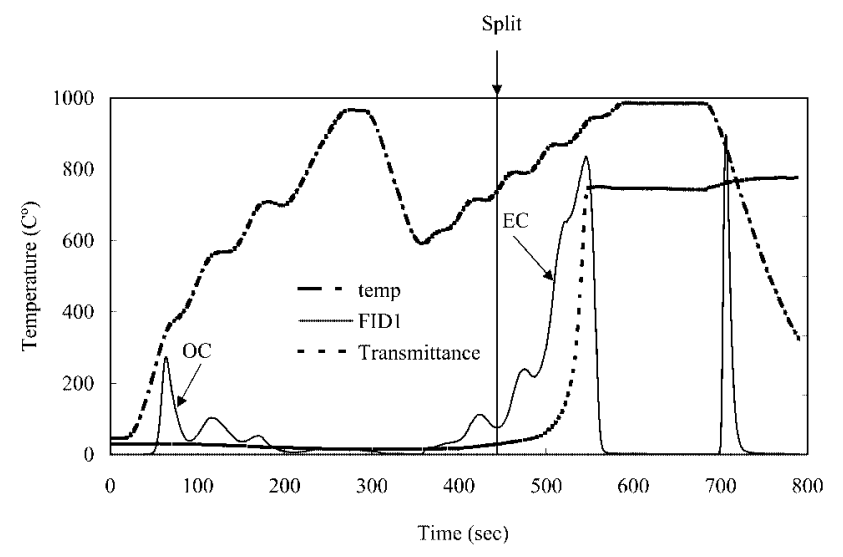

Fig. 1. OC and EC of NIST SRM 1650 by the NIOSH 5040 method.

is sensed by a $\mathrm{pH}$ electrode. Back titration was performed automatically to the initial $\mathrm{pH}$ and evolved carbon was calculated.

The NIOSH analytical method 5040 using FID is mainly used to monitor EC in the work environment ${ }^{38,39)}$. Similarly, an FID method is also used to evaluate ambient PM by a DRI (Desert Research Institute) method ${ }^{40)}$. One of the difficulties of thermal method is distinguishing EC present in the samples from polymeric organic substances and inorganic carbonate from natural sources which are charred and transformed into EC during the heat treatment procedure under helium. To overcome this problem, an optical correction method was introduced in the above methods. Two types of commercial instruments are available that can monitor either the transmittance or reflectance of a chopped $633 \mathrm{~nm}$ He-Ne laser light. The NIOSH method monitors transmittance for optical correction and the DRI method used reflection. For the NIOSH method, at the beginning of the analysis, the transmittance of the sample is measured. Under a helium atmosphere, as the temperature increases, organic material is volatilized and pyrolysis occurs to produce pyrolytic carbon, and the transmittance becomes lower. After the temperature is lowered for the second step of heating, oxygen is added and the pyrolytic carbon is oxidized to recover the transmittance. The point at which the value of transmittance becomes the same as the initial value is defined as "the split" between $\mathrm{OC}$ and $\mathrm{EC}$. The $\mathrm{CO}_{2}$ produced before the split is defined as OC, and after the split is defined as EC. The NIOSH method is mainly used to assess the elevated EC exposure due to DEP in working environments ${ }^{38,39)}$. However, it has also been applied to particles in the ambient air or in the exhaust from combustion sources ${ }^{29,30,43)}$.

Although the original concept of the NIOSH and DRI IMPROVE (Interagency Monitoring of Protected Visual
Environments) methods are similar, the temperature program is different. The reason for this difference is derived from the different aim of these instruments originally developed. For the NIOSH method, the protocol is designed to obtain the value of EC to evaluate or control occupational environment where diesel engines are being used, although accompanying results of OC and CC (carbonate carbon) are obtained. As each temperature step is programmed less than one minute, typical analytical procedure finishes in thirty minutes. A typical result obtained for NIST standard reference material of DEP (NIST SRM 1650) by NIOSH method (OCEC monitor, Sunset laboratory, Tigard, OR, USA) is shown in Fig. 1. The final peak of FID is a calibration peak of $\mathrm{CH}_{4}$ standard gas. On the other hand, the DRI IMPROVE method was developed to divide OC and EC into four and three groups (OC1-4 and EC 1-3), respectively. Each fraction is obtained at $120^{\circ} \mathrm{C}(\mathrm{OC} 1), 250^{\circ} \mathrm{C}(\mathrm{OC} 2)$, $450^{\circ} \mathrm{C}(\mathrm{OC} 3), 550^{\circ} \mathrm{C}(\mathrm{OC} 4)$ under helium, $550^{\circ} \mathrm{C}(\mathrm{EC} 1)$, $700^{\circ} \mathrm{C}(\mathrm{EC} 2)$ and $850^{\circ} \mathrm{C}(\mathrm{EC} 3)$ under $\mathrm{O}_{2} / \mathrm{He}$. These fractions represent different groups of carbon compounds, which vary by boiling points and thermal stability and can be used to indicate contributions from different emission sources for an approximate source apportionment of the collected particles $^{31}$. Temperature settings in this method are much lower than the NIOSH method. The duration of steps varies and depends on the width of the FID peak that evolves at a particular desorption step, therefore the measurement by DRI method takes one to two hours for one sample.

Several researches have conducted comparisons between thermal methods ${ }^{4-48)}$. The results for TC are usually coincident in contrast to the variations in the proportions of EC and OC in different methods. Without optical correction, the differences were mainly caused by the different temperature profiles of protocols used by each procedure ${ }^{44)}$. Some OC are charred at high temperatures without oxygen and make EC larger, a positive bias, if optical correction is not applied ${ }^{45)}$. In two thermal optical methods, fairly reasonable agreement on the value of EC was observed for common samples when they are operated with almost same protocol $^{46)}$. Conny et al. conducted an examination of the NIOSH method to evaluate the effect of temperature and duration of its protocol for three kinds of PM. They concluded that the most important factor affecting the $\mathrm{EC}$ value is the temperature of the fourth step during heating without oxygen. This step controls the positive bias from EC generated by charred OC. They examined various protocols and proposed an optimal protocol ${ }^{47)}$.

Chow et al. performed comparison of DRI method and $\mathrm{NIOSH}$ method examining the determination of each fraction 
of $\mathrm{OC}$ and $\mathrm{EC}^{48)}$. As the NIOSH method was originally developed to determine EC in the mining industry, the protocol is different from the DRI method. To obtain similar results for the DRI method, the NIOSH method is needed to be modified for various kind of samples. As the direction of light (reflectance or transmission) for optical correction is different for the two methods, the split of OC and EC was not same for very dark or very white samples.

Thermal optical correction methods are non-continuous, but ambient environmental monitoring for some applications requires a continuous method. There are two methods that are often used for the field measurements, which are semicontinuous. The carbon aerosol analyzer field instrument (Sunset laboratory, Tigard, OR, USA) uses a thermal-optical (transmittance) method, which is similar to the NIOSH method. After period of sampling of PM on quartz fiber filter, the loaded filter is treated by quick two step thermal program and evolved $\mathrm{CO}_{2}$ is monitored by $\mathrm{NDIR}^{49}$. This method has been applied for monitoring diurnal variation of EC and OC in ambient air, and for monitoring the air of Pacific Ocean using a ship ${ }^{50,51)}$.

Another semi-continuous instrument, the RP5400 (Rupprechet \& Patashnick, East Greenbush, NY, USA) measures the $\mathrm{CO}_{2}$ concentration released from a soot-bearing sample using a NDIR detector after the sample is oxidized at high temperatures in a sample collector, where soot-bearing particles are collected by impaction. The analytical program of this instrument consists of a collecting phase, and a subsequent analysis phase, during which the collector is heated up to oxidize the sample. To avoid a chronological sequence gap, the instrument has two collectors. The soot measuring device uses one of the collectors for current sampling, while the other is in the analysis phase of the previous collecting cycle. The collector is equipped with an impactor instead of filter. The $50 \%$ cut point diameter of the impactor is roughly $0.14 \mu \mathrm{m}$ aerodynamic particle diameter at a flow rate of about $16.7 \mathrm{~L} / \mathrm{min}$. In the original setting, the collector is maintained at $50^{\circ} \mathrm{C}$ to minimize the adsorption of gaseous and organic substances on the walls of the impactor. During the analysis phases the vaporized carbon compounds are converted to $\mathrm{CO}_{2}$ by post combustion. The lower and higher temperatures (for example $340^{\circ} \mathrm{C}$ and $750^{\circ} \mathrm{C}$ ) are defined as $\mathrm{OC}$ and EC. If a different intermediate temperature is chosen, different fraction of OC or EC are determined $^{52)}$.

A semi-continuous monitoring method without using thermal method is "Aethalometer", which was originally developed by Hansen et al. ${ }^{53,54)}$. The absorption of visible light by ambient aerosols is primarily due to the presence of graphitic carbon. The reduction of transmitted light intensity is proportional to the incremental surface loading of $\mathrm{BC}$ on the filter, with the coefficient being the optical attenuation cross section determined by the calibration. In this method $\mathrm{PM}$ is collected on a tape filter and light intensity is measured continuously. The difference of transmittance with or without sample is converted to the amount of $\mathrm{BC}$ with the attenuation coefficient determined for the instrument by a manufacturer. The relationship of $\mathrm{BC}$ and $\mathrm{EC}$, which were measured both NIOSH and DRI method, was compared in several researches ${ }^{55-57)}$. EC by filter sampling method was correlated the results of BC by Aethalometer for both DEP and ambient $\mathrm{PM}$ independent of the sampling sites. However, $\mathrm{BC}$ values were usually lower than that of $\mathrm{EC}$ by about 25 to $30 \%$. A conversion factor $(\mathrm{EC}=1.32 \times \mathrm{BC})$ was proposed by Babich et al..$^{55)}$ and it was applied by Borak et al. ${ }^{56)}$ to estimate $\mathrm{EC}$ from $\mathrm{BC}$ values. Important problems of this instrument are reportedly fluctuations of data from negative to positive especially caused by movements during traffic measurements and inaccuracies in the flow rate. Difficulties were also reported for monitoring moderate to high concentrations $(>0.050 \mathrm{mg} /$ $\mathrm{m}^{3}$ ) because a dilution system was needed to avoid coincidence errors and underestimates.

\section{PAH analysis}

An analytical method for PAHs in work environment air has been proposed by NIOSH ${ }^{58}$. For ambient air, Ministry of Environment, Japan ${ }^{59)}$ has proposed an analytical guideline for benzo(a)pyrene using high performance liquid chromatography (HPLC), and the United States Environmental Protection Agency (USEPA) ${ }^{60}$ has adopted a gas chromatography/mass spectrometry (GC/MS) method. In general, the analysis of PAH in PM has been conducted by the following procedure: PAHs in PM collected on filters are extracted into an appropriate solvent by Soxleht extraction, and the extracts are concentrated. Determination is carried out with HPLC/ultraviolet detector and/or fluorescent detector, or with GC/MS.

The extraction method has been modified by sonication ${ }^{61)}$, accelerated solvent extraction (ASE) ${ }^{62,63)}$ or changed to super critical fluid extraction (SCFE) using carbon dioxide ${ }^{62}$, to shorten the extraction time and reduce the volume of extraction solvent. Sonication is convenient, reduces the extraction time and the solvent volume, however, PAHs of higher molecular weight is less extractable ${ }^{61)}$. PAHs extracted by ASE coincide with those by Soxleht extraction if suitable extraction procedure is selected. The drawbacks of ASE is volume of extracts is unknown, thus concentration procedure 
is necessary. In SCFE, concentration procedure is easy and an organic solvent is not used. However, a special apparatus is required.

Analysis of PAHs with HPLC-uv detector has been mainly used to determine PAHs since 1970's. Some PAHs show strong fluorescence, thus high sensitivity is achieved using a fluorescent detector. Takahashi et al $^{61)}$ modified HPLC method to determine PAHs automatically with high sensitivity, for example, $3 \mathrm{pg}$ of benzo(a)pyrene can be detected. This method has a concentration and clean-up procedure followed by HPLC/fluorometer analysis, in which activation and fluorescence wavelengths are optimized for each PAH, so seven kinds of PAHs can be analyzed continuously. To monitor nitroarenes in the ambient air, HPLC/chemiluminescence ${ }^{64)}$ or HPLC/MS/MS ${ }^{65}$ are used. With these traditional methods, the use of solvent is inevitable and extraction efficiency is dependent on the chemical properties of the extraction solvent, properties of the PM and the desired PAH analytes.

Recently, thermal desorption techniques for extracting volatile and semivolatile organic compounds have been introduced to analyze organic chemical substances in airborne PM by GC/FID and GC/MS as an alternative to the solvent extraction technique. The thermal desorption with GC/MS techniques are more convenient than above-mentioned traditional off-line techniques, because the time-consuming sample extraction process is not required and smaller samples may be used. Neusuess et al. ${ }^{66)}$ developed a thermal desorption technique based on pyrolysis. However, pyrolysis outside the GC injector generally results in loss of compounds on the tubing walls of the transfer line. Helmig et al. ${ }^{67)}$ modified a conventional GC injector to enable the insertion of loaded filter samples without affecting the performance of the GC-system. Sigman and $\mathrm{Ma}^{68)}$ developed a gas chromatographic method utilizing thermal desorption from a dry surface wipe for the analysis of explosives, trace chemical evidence. In this method, surface-abraded Teflon tubing was used for sample collection, and the tube was inserted into an injector of GC to desorb volatile or semivolatile organic compounds thermally. Waterman et al. ${ }^{69-71)}$ developed a micro-scale sealed vessel for thermal desorption of PAHs into the vapor phase, which were then transferred into a GC/MS for analysis. They validated the quantitative vaporization of PAHs in airborne PM using NIST standard reference material. Jing and Amirav's group ${ }^{72,73)}$ developed a direct sample introduction (DSI) device for the analysis of trace amounts of semivolatile organic components in PM. The sample is placed in a tiny sample vial that is inserted into GC injector. After sample introduction, the semivolatile

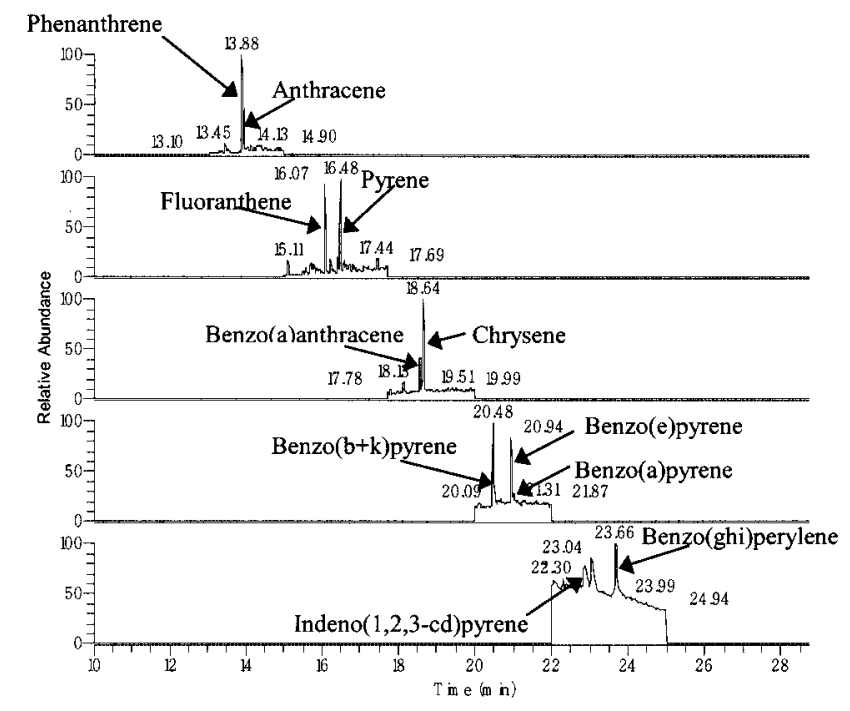

Fig. 2. A chromatogram of PAHs on NIST SRM 1650 analyzed by direct injection-thermal desorption GC/MS (Sample amount: $46.6 \mu \mathrm{g}$ ).

organic compounds are thermally desorbed directly in the injector liner. Falkovich and Rudich ${ }^{74)}$ reported an assessment of the DSI technique for the analysis of semivolatile organic compounds in atmospheric particles, which showed that they can achieve nearly $100 \%$ desorption efficiency for phenanthrene, fluoranthene and pyrene. A newly developed direct injection-thermal desorption method was applied to analyze PAHs in DEP standard reference materials by Ono-Ogasawara et al. and a chromatogram of NIST SRM 1650 is shown in Fig. $2^{75}$.

\section{UV-PAS}

It is a considerable interest to use an analytical method with the ability of in situ and on-line detection of particulate PAHs, as traditional methods of PAH analysis are cumbersome, time consuming, and expensive processes. A technique that partially meets these requirements is the photoelectric charging of ultrafine PAH-coated particles with the photoelectric aerosol sensor (PAS). The operational principle of PAS is described in detail by Burtscher ${ }^{76)}$. The PAS responds to photoemitting substances on the surface of aerosol particles. Ultraviolet irradiation of the sampled aerosol leads to the emission of photoelectrons from surface materials. The remaining positively charged aerosol particles are collected on a filter connected to an electrometer, which measures the current produced. Commercially available instruments usually use a wavelength of $222 \mathrm{~nm}$ produced by the $\mathrm{Kr}-\mathrm{Br}$ excimer lamp. Particle bound PAHs are 
particularly suitable for measurement by photoelectric charging. Niessner ${ }^{77,78)}$ reported that PAH with more than four rings containing large $\pi$-electron systems have lower first ionization potentials than smaller PAHs, and are thus more easily photoionized. Burtscher ${ }^{79)}$ reported that the probability of back diffusion of photoelectrons to particulate surface is lowest for particles that are small compared to the mean free path of electrons in the gas, and the upper limit of particle diameter for efficient charging is ca. $1 \mu \mathrm{m}$. USEPA showed that gas-phase PAH with 2-4 rings are not detected by PAS ${ }^{80}$. Thus PAS measures PAH adsorbed on particles having an aerodynamic diameter less than approximately $1 \mu \mathrm{m}$. PAS is, however, a developing technology and problematic in some aspects, particularly regarding instrument calibration and potential response variability by PAH composition. Although photoelectric responses from different PAH species were found to be additive in a laboratory study ${ }^{77,78)}$. PAS calibration is still be both difficult and uncertain because different PAH species exhibit somewhat different ionization potentials and the PAH composition of the targeted PM may not be known.

The other important effect for PAS is associated with EC from diesel emissions. Diesel accumulation mode particles strongly respond to the PAS ${ }^{81,82)}$. It was originally believed that PAHs show a high photoelectric yield, causing a high PAS signal, while EC has a significantly lower photoelectric yield and showed only a moderate PAS response ${ }^{32,83)}$. The sensitivity for EC is dependant on the wavelength of uv light for excitation. For example, the EC value excited with172 $\mathrm{nm}$ is almost two times larger than that of $222 \mathrm{~nm}^{32}$. Further, the diesel accumulation mode particles has such a high EC concentration that the contribution of EC on the PAS response is considered to be higher than of $\mathrm{PAH}^{17}$. For the environment with high concentration of diesel exhaust particles, such as construction work environment, the effect of EC on the result of PAS response should be considered. On the other hand, in mixed urban aerosols, the PAH contribution to the PAS response should be higher because of its lower EC content. The USEPA has conducted a PAS evaluation and reported positively on its performance ${ }^{80)}$. PAS signals can be quantitatively interpreted only in a certain contexts where integrated PAH data is available, because producing a general calibration method for PAS is difficult. Nevertheless realtime PAS signal observations are useful for monitoring of relative changes of ultrafine particles especially from combustion sources. Despite these drawbacks, PAS has been used to measure PAH levels for tobacco smoke ${ }^{84)}$, ambient air $^{85)}$, and diesel exhaust ${ }^{81,86}$. Field calibration studies have shown that there is a nearly linear relationship between the
PAS signal and PAH levels measured in samples of PM collected on filters from ambient air $^{83)}$.

\section{Summary}

Occupational exposure to diesel engine exhaust has been a great concern because the particles contain toxic components, the exposures are widespread, and the concentrations of contaminants can be very high at times, especially where the work environment is confined. There is a growing literature that suggests that there are a variety of health effects linked with DEP exposures, such as lung cancer, heart disease and asthma in children. Until recently, only real-time monitoring methods for gases, such as nitrogen oxide, have been available for characterizing exposures in the work environment, however, several potentially useful quick and real-time monitoring methods for DEP have been developed and evaluated. Engines' modifications and new fuels, and particle filters are expected to reduce the level of DEP emissions, which will make monitoring mass of DEP more difficult, thus other than mass monitoring methods are needed. In this article, state-of-the-art technology to measure DEP from the point of view of chemical components, such as EC and PAHs, were reviewed. By these new methods, faster or real-time evaluation of PAHs may be achieved and more sensitive measurement of DEP can be accomplished. Monitoring methods based on physical properties of ultrafine or nano-size DEP, such as number, size, surface area, and so on, are also being developed. Combined use of various method should improve monitoring of DEP and lead to improved work environments where diesel engines are used.

\section{Acknowledgements}

The authors thank Dr. Toshihiko Myojo (National Institute of Industrial Health) for his suggestion to prepare this review.

\section{References}

1) International Agency for Research on Cancer (1989) IARC monographs on the evaluation of carcinogenic risks to humans: vol. 46. IARC, Lyon, France.

2) United States Environmental Protection Agency (2002) Health assessment document for diesel engine exhaust, National center for environmental assessment office of research and development. United States Environmental Protection agency, Washington, DC.

3) Miyabara Y, Takano H, Ichinose T, Lim HB, Sagai M (1998) Diesel exhaust enhances allergic airway 
inflammation and hyperresponsiveness in mice. Am J Respir Crit Care Med 157, 1138-44.

4) Watanabe N, Oonuki Y (1999) Inhalation of diesel engine exhaust affects spermatogenesis in growing male rats. Environ Health Perspect 107, 539-44.

5) Watts Jr WF (1995) Assessment of occupational exposure to diesel emissions. In: Diesel exhaust: a critical analysis of emissions, exposure, health effects. pp. 109-23, Health Effects Institute, Cambridge, MA.

6) Ministry of Land, Infrastructure and Transport of Japan (2001) Partial amendment of the safety standard for road trucking vehicle, August 2001. Tokyo (in Japanese).

7) Ministry of Labour of Japan (2001) The guideline of control measures for particulate matter for tunnel construction, December 2001. Tokyo (in Japanese).

8) Bakke B, Stewart P, Ulvestad B, Eduard W (2001) Dust and gas exposure in tunnel construction work. Am Ind Hyg Assoc J 62, 457-65.

9) Whittaker LS, MacIntosh DL, Williams PL (1999) Employee exposure to diesel exhaust in the electric utility industry. Am Ind Hyg Assoc J 60, 635-40.

10) Zaebst DD, Clapp DE, Blade LM, Marlow DA, Steenland K, Hornung RW, Scheutzle D (1991) Quantitative determination of trucking industry workers' exposures to diesel exhaust particles. Am Ind Hyg Assoc J 52, 529-41.

11) Steenland K, Deddens J, Stayner L (1998) Diesel exhaust and lung cancer in the trucking industry: exposure-response analyses and risk assessment. Am J Ind Med 34, 220-8.

12) Stayner L, Dankovic D, Smith R, Steenland K (1998) Predicted lung cancer risk among miners exposed to diesel exhaust particles. Am J Ind Med 34, 207-19.

13) Morgan WKC, Reger RB, Tucker DM (1997) Health effects of diesel emissions. Ann Occup Hyg 41, 64358.

14) Larkin EK, Smith TJ, Stayner L, Rosner B, Speizer FE, Garshick E (2000) Diesel exhaust exposure and lung cancer: adjustment for the effect of smoking in a retrospective cohort. Am J Ind Med 38, 399-409.

15) Jongeneelen FJ (1997) Methods for routine biological monitoring of carcinogenic PAH-mixtures. Sci Total Environ 199, 141-9.

16) Chow JC (1995) Measurement methods to determine compliance with ambient air quality standards for suspended particles. J Air Waste Manag Assoc 45, 32082.

17) Kittelson DB (1998) Engines and nanoparticles: a review. J Aerosol Sci 29, 575-88.
18) Donaldson K, Li XY, MacNee W (1998) Ultrafine (nanometre) particle mediated lung injury. J Aerosol Sci 29, 553-60.

19) Obersdoerster G (1996) Significance of particle parameters in the evaluation of exposure-dose-response relationships of inhales particles. Inhal Toxicol 8 (Suppl), 73-89.

20) Morrow PE (1998) Possible mechanisms to explain dust overloading of the lungs. Fund Appl Toxicol 10, 36984.

21) Mauderly JL (1997) Relevance of particle-induced rat lung tumors for assessing lung carcinogenic hazard and human lung cancer risk. Environ Health Perspect 105 (Suppl 5), 1337-46.

22) Dockery DW, Pope CA III, Xu XP, Spengler DJ, Ware HJ, Fay EM, Ferris GB, Speizer EF (1993) An association between air pollution and mortality in six U.S. cities. New Eng J Med 329, 1753-9.

23) Schwartz J, Dockery DW, Neas LM (1996) Is daily mortality associated specifically with fine particles? J Air Waste Manag Assoc 46, 927-39.

24) Ishiguro T, Takatori Y, Akihama K (1997) Structure of diesel soot particles probed by electron microscopy: first observation of inner core and outer shell. Combust Flame 108, 231-4.

25) Yamasaki H, Kuwata K, Miyamoto H (1982) Effects of ambient temperature on aspects of airborne polycyclic aromatic hydrocarbons. Environ Sci Technol 16, 189-94.

26) Ligocki MP, Pankow JF (1989) Measurements of the gas/particle distributions of atmospheric organic compounds. Environ Sci Technol 23, 75-83.

27) Finlayson-Pitts BJ, Pitts JN Jr (1999) Polycyclic aromatic carbon (chapter 10). In: Chemistry of the Upper and Lower Atmosphere, 436-546, Academic Press, San Diego, CA.

28) Tokiwa H, Ohnishi Y (1986) Mutagenicity and carcinogenicity of nitroarenes and their sources in the environment. CRC Crit Rev Toxicol 17, 23-60.

29) Schauer JJ, Cass GR (2000) Source apportionment of wintertime gas-phase and particle-phase air pollutants using organic compounds as tracers. Environ Sci Technol 34, 1821-32.

30) Schauer JJ, Rogge WF, Hildemann LM, Mazurek MA, Cass GR, Simoneit BRT (1996) Source apportionment of airborne particulate matter using organic compounds as tracers. Atmos Environ 30, 3837-55.

31) Chow JC, Watson JG, Kuhns H, Etyemezian V, Lowenthal DH, Crow D, Kohl SD, Engelbrecht JP, 
Green MC (2004) Source profiles for industrial, mobile, and area sources in the Big Bend Regional Aerosol Visibility and Observational study. Chemosphere 54, 185-208.

32) Dahmann D, Matter U, Mosimann $T$ (2002) The photoelectrical aerosol sensor (PAS), a novel direct reading sensor system for diesel engine emissions. Gefahrstoffe-Reinhaltung der Luft 62, 7-11 (in German).

33) Cadle SH, Mulawa PA (1990) Atmospheric carbonaceous species measurement methods comparison study: general moters results. Aerosol Sci Technol 12, 128-41.

34) Fung K (1990) Particulate carbon speciation by $\mathrm{MnO}_{2}$ oxdation. Aerosol Sci Technol 12, 122-7.

35) Mizohata A, Ito N, Masuda Y (1995) Quantitative determination of the airborne particulate matter sources by motor vehicles using TTFA. J Japan Soc Atmos Environ 30, 243-55 (in Japanese).

36) Verfahren zur Bestimmung von Kohlenstoffen im Feinstaub-anwendbar für partikelförmige Dieselmotor-Emissionen in Arbeitsbereichen-(BGI 505-44) Bezugsquelle: Carl Heymanns Verlag KG, Luxemburger Straße 449, 50939 Köln.

37) Bauer H-D, Dahmann D, Fricke H-H (1991) Coulometric determination of diesel-engine-emissions in non-coal mines. Staub Reinhalt Luft 51, 319-25 (in German).

38) Birch ME, Cary RA (1996) Elemental Carbon-based method for monitoring occupational exposures to particulate diesel exhaust. Aerosol Sci Technol 25, 221-4.

39) National Institute of Occupational Safety and Health (1999) Method 5040 Issue 3 (Interim) Elemental Carbon (Diesel Exhaust). In: NIOSH Manual of Analytical Methods. NIOSH, Cincinnati, $\mathrm{OH}$.

40) Chow JC, Watson JG, Pritchett LC, Pierson WR, Frazier CA, Purcell RG (1993) The DRI thermal/optical reflectance carbon analysis system: description, evaluation and applications in U.S. Air quality studies. Atmos Environ 27A, 1185-201.

41) Whittacker LS, MacIntosh, Williams PL (1999) Employee exposure to diesel exhaust in the electric utility industry. Am Ind Hyg Assoc J 60, 635-40.

42) Bakke B, Stewart P, Ulvestad B, Eduard W (2001) Dust and gas exposure in tunnel constrction work. Am Ind Hyg Assoc J 62, 457-65.

43) Hildemann LM, Markowski GR, Cass GR (1991) Chemical composition of emissions from urban sources of fine organic aerosols. Environ Sci Technol 25, 744-59.

44) Guillemin M, Perret V, Dabill D, Grosjean R, Dahmann D, Hebisch R (2001) Further round-robin tests to improve the comparability between laboratories of the measurement of carbon in diesel soot and in environmental samples. Int Arch Occup Environ Health 74, 139-47.

45) Birch ME, Dahmann D, Fricke HH (1999) Comparison of two carbon analysis methods for monitoring diesel particulate levels in mines. J Environ Monit 1, 541-54.

46) Birch ME (1998) Analysis of carbonaceous aerosols: interlaboratory comparison. Analyst 123, 851-7.

47) Conny JM, Klinedinst DB, Wight SA, Paulsen JL (2003) Optimizing thermal-optical methods for measuring atmospheric elemental (black) carbon: a response surface study. Aerosol Sci Technol 37, 703-23.

48) Chow JC, Watson JG, Crow D, Lowenthal DH, Merrifield T (2001) Comparison of IMPROVE and NIOSH carbon measurements. Aerosol Sci Technol 34, 23-34.

49) Turpin BJ, Cary RA, Huntzicker JJ (1990) An in-situ, time-resolved analyzer for aerosol organic and elemental carbon. Aerosol Sci Technol 12, 161-7.

50) Turpin BJ, Huntzicker JJ (1995) Identification of secondary organic aerosol episodes and quantitation of primary and secondary organic aerosol concentrations during SCAQS. Atmos Environ 29, 3527-44.

51) Lim H-J, Turpin BJ, Russell LM, Bates TS (2003) Identification of secondary organic aerosol episodes and quantitation of primary and secondary organic aerosol concentrations during SCAQS. Environ Sci Technol 37, 993-1001.

52) Rupprecht EG, Patashnick H, Beeson DE, Green RE, Meyer MB (1995). A new automated monitor for the measurement of particulate carbon in the atmosphere. In: Proceedings, Particulate Matter: Health and Regulatory Issues, eds. by Cooper J.A., Grant L.D. 2627. Air and Waste Management Association, Pittsburgh, PA.

53) Hansen ADA, Rosen H, Novakov $T$ (1984) The aethalometer-an instrument for the real-time measurement of optical absorption by aerosol particles. Sci Total Environ 36, 191-6.

54) Hansen ADA, Novakov $T$ (1990) Real-time measurement of aerosol black carbon during the carbonaceous species methods comparison study. Aerosol Sci Technol 12, 194-9.

55) Babich P, Davey M, Allen G, Koutrakis P (2000) Method 
comparisons for particulate nitrate, elemental carbon, and PM2.5 mass in seven U.S. cities. J Air Waste Manag Assoc 50, 1095-105.

56) Borak J, Sirianni G, Cohen HJ, Chemerynski S, Wheeler R (2003) Comparison of NIOSH 5040 method versus aethalometer to monitor diesel particulate in school buses and at work sites. Am Ind Hyg Assoc J 64, 260-8.

57) Allen GA, Lawrence J, Koutrakis P (1999) Field validation of a semi-continuous method for aerosol black carbon (aethalometer) and temporal patterns of summertime hourly black carbon measurements in southwestern PA. Atmos Environ 33, 817-23.

58) National Institute of Occupational Safety and Health (1999) Method 5506 Issue 3. Polynuclear aromatic hydrocarbons by HPLC. In: NIOSH Manual of Analytical Methods. NIOSH, Cincinnati, $\mathrm{OH}$.

59) Ministry of Environment of Japan (1998) Analytical manual of toxic airborne chemical substances. Tokyo (in Japanese).

60) U.S. Environmental protection agency (1999) Compendium method TO-13A: Determination of polycyclic aromatic hydrocarbons (PAHs) in ambient air using gas chromatography/mass spectrometry $(\mathrm{GC} /$ MS). In: Compendium of methods for the determination of toxic organic compounds in ambient air. 2nd ed., USEPA, Cincinnati, $\mathrm{OH}$.

61) Takahashi Y, Amagai T, Matsushita H (1997) A highly sensitive and automatic analytical method for carcinogenic polycyclic aromatic hydrocarbons (PAHs) in indoor airborne particulates. J Environ Chem 7, 8219 (in Japanese).

62) Hawthorne SB, Grabanski CB, Martin E, Miller DJ (2000) Comparisons of Soxhlet extraction, pressurized liquid extraction, SFE and subcritical water extraction for environmental solids. J Chromtgr A 892, 421-43.

63) Alexandrou N, Park R, Lumb K, Brick K (2002) The extraction of polycyclic aromatic hydrocarbonas from atmospheric particulate matter samples by accelerated solvent extraction(ASE). Int J Environ Anal Chem 81, 257-80.

64) Murahashi T, Ito M, Kizu R, Hayakawa K (2001) Determination of nitroarenes in precipitation collected in Kanazawa, Japan. Water Res 35, 3367-72.

65) Kawanaka Y, Wang Y, Yun S, Sakamoto K (2002) Size distribution and seasonal variations in concentrations of 1-nitropyrene and polycyclic aromatic hydrocarbons in atmospheric particulate matter. J Environ Chem 12, 599-607 (in Japanese).

66) Neusuess C, Pelzing M, Plewka A, Herrmann H (2000)
A new analytical approach for size — resolved speciation of organic compounds in atmospheric aerosol particles: methods and first results. J Geophys Res 105, 4513-27.

67) Helmig D, Bauer A, Mueller J, Klein W (1990) Analysis of particulate organics in a forest atmospherer by thermodesorption GC/MS. Atmos Environ 24A, 17984.

68) Sigman ME, Ma CY (1999) In-injection port thermal desorption for explosives trace evidence analysis. Anal Chem 71, 4119-24.

69) Hall PA, Watson AFR, Garner GV, Hau K, Smith S, Waterman D, Horsfield B (1999) An investigation of micro-scale sealed vessel thermal extraction-gas chromatography-mass spectrometry (MSSV-GC-MS) and micro-scale sealed vessel pyrolysis-gas chromatography-mass spectrometry applied to a standard reference material of an urban dust/organics. Sci Total Environ 235, 269-76.

70) Waterman D, Horsfield B, Leistner F, Hall K, Smith $S$ (2000) Quantification of polycyclic aromatic hydrocarbons in the NIST standard reference material (SRM1649a) urban dust using thermal desorption GC/ MS. Anal Chem 72, 3563-7.

71) Waterman D, Horsfield B, Hall K, Smith S (2001) New method for rapid solid-phase extraction of large-volume water samples and its application to non-target screening of North Sea water for organic contaminants by gas chromatography—mass spectrometry. J Chromatog A 912, 143-50.

72) Jing H, Amirav A (1997) Pesticide analysis with the pulsed-flame photometer detector and a direct sample introduction device. Anal Chem 69, 1426-35.

73) Amirav A, Dagan SA (1997) Direct sample introduction device for mass spectrometry studies and gas chromatography mass spectrometry analyses. Eur Mass Spectrom 3, 105-111.

74) Falkovich AH, Rudich $Y$ (2001) Analysis of semivolatile organic compounds in atmospheric aerosols by direct sample introduction thermal desorption GC/MS. Environ Sci Technol 35, 2326-33.

75) Ono-Ogasawara M, Myojo T, Smith TJ, Environ Sci Technol (submitted).

76) Burtscher H (1992) Measurement and characteristics of combustion aerosols with special consideration of photoelectric charging and charging by flame ions. $\mathrm{J}$ Aerosol Sci 23, 549-95.

77) Niessner R, Wilbring P (1989) Ultrafine particles as trace catchers for polycyclic aromatic hydrocarbons: the photoelectric aerosol sensor as a tool for in situ sorption 
and desorption studies. Anal Chem 61, 708-14.

78) Niessner R, Hemmerich B, Wilbring P (1990) Aerosol photoemission for quantification of polycyclic aromatic hydrocarbons in simple mixtures adsorbed on carbonaceous and sodium chloride aerosols. Anal Chem 62, 2071-4.

79) Burtscher H, Schmidt-Ott A (1986) In situ measurement of adsorption and condensation of a polyaromatic hydrocarbon on ultrafine $\mathrm{C}$ particles by means of photoemission. J Aerosol Sci 17, 699-703.

80) Ramamurthi M, Chuang JC (1997) Field and laboratory evaluations of a real-time PAH analyzer, EPA/600/R97/034, U.S. EPA.

81) Matter U, Siegmann HC, Burtscher H (1999) Dynamic field measurements of submicron particles from diesel engines. Environ Sci Technol 33, 1946-52.

82) Bukowiecki N, Kittelson DB, Watts WF, Burtscher H, Weingartner E, Baltensperger U (2002) Real-time characterization of ultrafine and accumulation mode particles in ambient combustion aerosols. J Aerosol Sci 33, 1139-54.

83) Siegmann K, Siegmann HC (2000) Fast and reliable "in-situ" evaluation of particles and their surfaces with special reference to diesel exhaust. SAE Technical Paper series, 2000-01-1995, SAE Internatioal, Warrendale, PA U.S.A.

84) Dubowsky SD, Wallace LA, Buckley TJ (1999) The contribution of traffic to indoor concentrations of polycyclic aromatic hydrocarbons. J Expos Anal Environ Epidemiol 9, 312-21.

85) Dunbar JC, Lin C-I, Vergucht I, Wong J, Durant JL (2001) Estimating the contributions of mobile sources of PAH to urban air using real-time PAH monitoring. Sci Total Environ 279, 1-19.

86) Weingartner E, Keller C, Stahel WA, Burtscher H, Baltensperger U (1997) Aerosol emission in a road tunnel. Atoms Environ 31,451-62. 